\title{
New developments of influenza surveillance in Europe
}

R Snacken (rene.snacken@ecdc.europa.eu) ${ }^{1}, \mathrm{C}$ Brown²

1. European Centre for Disease Prevention and Control (ECDC), Stockholm, Sweden

2. World Health Organisation Regional Office for Europe, Copenhagen, Denmark

Citation style for this article:

Snacken R, Brown C. New developments of influenza surveillance in Europe. Euro Surveill. 2015;20(4):pii=21020. Available online: http://www.eurosurveillance. org/ViewArticle.aspx?Articleld $=21020$

Article published on 29 January 2015

The influenza season 2014/15 has started in Europe [1] and developments can be followed closely via the joint European Centre for Disease Prevention and Control (ECDC) and World Health Organization (WHO) influenza bulletin. The bulletin was launched in October 2014 and is available from www. flunewseurope.org .

All 53 European countries have been invited to report through the single joint entry point to the European Surveillance System (TESSy), the ECDC system for reporting data. Data from TESSy are then used to publish the joint weekly bulletin in English and Russian. Data transfer to the WHO global platforms FluNet and FluID will continue to be managed by the WHO Regional Office for Europe.

Since week 40 in 2014, 53 European countries have the opportunity to report influenza surveillance data to a single platform with the analysis posted in a new European joint weekly bulletin as well as in the WHO global influenza update. Extended influenza surveillance in Europe will provide more data to better estimate the burden of the disease.

The new bulletin includes features such as a format for interactive consultation by country, and a better description of data sets from different surveillance systems.

Collaboration among European countries for creating a harmonised network of influenza surveillance started in the 1990 s and has evolved incrementally with additional countries and extended objectives [2]. Since 2008, the European Influenza Surveillance Network (EISN), covering 30 EU/EEA countries, has been managed by the ECDC. In parallel, the WHO Regional Office for Europe has been covering the 53 countries of the European Region, including all EU/EEA countries. In this structure, countries initially reported data derived from sentinel and other clinical and laboratory surveillance systems via two different platforms. Each organisation has also published separate bulletins (the Weekly Influenza Surveillance Overview and Euroflu, respectively). This dual reporting resulted in unavoidable discrepancies [3].
In 2010, the European Surveillance System (TESSy), was established at ECDC as a single data entry point in order to synchronise reporting for both platforms [4] and in 2014, based on feedback from key stakeholders, ECDC and the WHO Regional Office for Europe decided to publish a single joint influenza bulletin for the WHO European Region and EU/EEA Member States.

Activities of the influenza surveillance will continue to be streamlined by means of influenza surveillance meetings, ad hoc working groups to tackle specific topics and a range of laboratory strengthening activities including external quality assessment and training.

References

1. Broberg E, Snacken R, Adlhoch C, Beauté J, Galinska M, Pereyaslov D, Brown C, Penttinen P. Start of the 2014/15 influenza season in Europe: drifted influenza $A\left(\mathrm{H}_{3} \mathrm{~N}_{2}\right)$ viruses circulate as dominant subtype. Euro Surveill. 2015;20(4):pii=21023. Available online: http://www. eurosurveillance.org/ViewArticle.aspx?Articleld=21023

2. Fleming DM, van der Velden J, Paget WJ. The evolution of influenza surveillance in Europe and prospects for the next 10 years. Vaccine. 2003;21:1749-53 http://dx.doi.org/10.1016/ So264-410X(03)00066-5

3. Johnson H, Meeyai A, Cocker R. Potential for greater coherence in European influenza surveillance. Influenza surveillance in Europe. Eur J Public Health. 2010;20(5):488-9 http://dx.doi. org/10.1093/eurpub/ckq124

4. Snacken R, Zucs P, Brown C, Jorgensen P, Mott JA, AmatoGauci A. Influenza surveillance in Europe. Eur J Public Health. 2011;21(5):674-5 http://dx.doi.org/10.1093/eurpub/ckq185 